\title{
Correction to the Special Section on Attachment and Psychopathology. Part 1
}

There was a serious omission to the February 1996 issue of the Journal of Consulting and Clinical Psychology (Vol. 64, No. 1, pp. 5-73).

Mary Main and Rebecca del Carmen were co-authors with Enrico E. Jones of Part 1 of the special section on attachment and psychopathology, which appeared in the February issue. Their names did not appear in the special section heading in the table of contents, although they are co-editors of both Parts 1 and 2. A corrected listing of the special section contents is shown below. The production office deeply regrets the error.

Special Section: Attachment and Psychopathology, Part 1 Guest Editors: Enrico E. Jones, Mary Main, and Rebecca del Carmen

5 Introduction to the Special Section on Attachment and Psychopathology: Part 1

Enrico E. Jones

8 Attachment Representations in Mothers, Fathers, Adolescents, and Clinical Groups: A Meta-Analytic Search for Normative Data

Marinus H. van IJzendoorn and Marian J. Bakermans-Kranenburg

22 The Relation of Attachment Status, Psychiatric Classification, and Response to Psychotherapy

Peter Fonagy, Tom Leigh, Miriam Steele, Howard Steele, Roger Kennedy, Gretta Mattoon, Mary Target, and Andrew Gerber

32 Patterns of Relatedness, Depressive Symptomatology, and Perceived Competence in Maltreated Children Sheree L. Toth and Dante Cicchetti

42 Beyond Insecurity: A Reconceptualization of Attachment Disorders of Infancy Charles H. Zeanah

53 Parents' Attachment Histories and Children's Externalizing and Internalizing Behaviors: Exploring Family Systems Models of Linkage

Philip A. Cowan, Deborah A. Cohn, Carolyn Pape Cowan, and Jane L. Pearson

64 Attachment Relationships Among Children With Aggressive Behavior Problems: The Role of Disorganized Early Attachment Patterns

Karlen Lyons-Ruth 